\title{
UM RELATO DE CASO SOBRE A CONSTRUÇÃO E ELABORAÇÃO DO PORTFÓLIO COMO METODOLOGIA AVALIATIVA DE APRENDIZAGEM ${ }^{1}$
}

\section{A CASE REPORT ON THE CONSTRUCTION AND PREPARATION OF A PORTFOLIO AS A LEARNING ASSESMENT METHOD}

\section{UN RELATO DE CASO SOBRE CONSTRUCCIÓN Y PREPARACIÓN DEL PORTAFOLIO COMO METODOLOGÍA EVALUATIVA DE APRENDIZAJE}

\author{
Letice Dalla Lana* \\ JuCELINE AREND BIRNER*
}

\begin{abstract}
RESUMO
Objetivo: Relatar a experiência de construção do portfólio como método de avaliação e aprendizagem prático teórico de um Programa de Residência Multiprofissional em Sistema Público de Saúde por uma residente enfermeira. Método: O período ocorreu de 2010 a 2012, perfazendo os períodos de construção, elaboração e avaliação do portfólio, visando potencialidades e dificuldades na perspectiva do residente. Resultados: Identificou-se que mesmo diante de obstáculos referentes à metodologia adotada, o portfólio se mostrou uma ferramenta de avaliação eficaz na residência, conectada a um processo em evolução e não apenas a um momento particular do desenvolvimento do residente. Conclusão: O portfólio possibilita um pensar critico-reflexivo que culmine em mudanças comportamentais nas práticas desenvolvidas pelo residente diante das atividades profissionais preconizado pelo projeto político pedagógico do programa de residência multiprofissional. Além disso, constrói um profissional desprovido do modelo tradicional do fazer saúde.
\end{abstract}

Palavras chave: Portfólio, ensino, aprendizagem, educação em enfermagem, pesquisa em educação de enfermagem.

\section{ABSTRACT}

Objective: The aim of this study is to report on the experience of a resident nurse in the construction of a portfolio as an assessment method and theoretical practical learning in the context of a multidisciplinary residency program in the Public Health System. Method: The period lasted from 2010 to 2012, including construction, development and assessment of the portfolio and taking into account chances and difficulties according to the resident nurse's perspective. Results: It was reported that even in the face of obstacles related to methodology, the portfolio proved an effective assessment tool during residency, as it related to a continuous process and not just a particular moment in the development of the resident nurse. Conclusion: The portfolio contributes to a critical and reflective thinking allowing behavioral changes in practices developed by the resident nurse in their professional activities, as established by the residency program's political and educational objectives.

Key words: Portfolio, teaching, learning, education, nursing, nursing education research.

${ }^{1}$ Texto inédito. Relato de caso vivenciado durante o Programa de Residência Multiprofissional em Sistema Público de Saúde da Universidade Federal de Santa Maria (UFSM), entre 2010 e 2012. Não há conflito de interesse neste manuscrito. * Enfermeira. Universidade Federal do Rio Grande do Sul, Porto Alegre, Rio Grande do Sul, Brasil (UFRGS/RS). Email: leticedl@hotmail.com

${ }^{* *}$ Enfermeira. Universidade Federal de Santa Maria, Santa Maria, Rio Grande do Sul, Brasil (UFSM/RS). Email: juarend@ ibest.com.br 


\section{RESUMEN}

Objetivo: Reportar la experiencia de una enfermera residente en la construcción de un portafolio como método de evaluación y la teoría del aprendizaje práctico de un Programa de Residencia multidisciplinar en el Sistema Público de Salud. Material y método: El período fue de 2010 a 2012, perfeccionando los períodos de construcción, desarrollo y evaluación del portafolio, potencialidades y dificultades en la perspectiva del residente. Resultados: Se encontró que, a pesar de los obstáculos relacionados con la metodología, el portafolio mostró ser una herramienta de evaluación eficaz en la residencia, conectado a un proceso continuo y no un momento particular del desarrollo de residente. Conclusión: El portafolio posibilita un pensamiento crítico y reflexivo que culmina en cambios de comportamiento en las prácticas desarrolladas por el residente en sus actividades profesionales recomendados por el proyecto político pedagógico del programa de residencia multidisciplina. Además, construye un profesional desprovisto del modelo tradicional de hacer salud.

Palabras clave: Portafolio, enseñanza, aprendizaje, educación en enfermería, investigación en educación de enfermería.

Fecha recepción: 12/07/13 Fecha aceptación: 21/12/14

\section{INTRODUÇÃO}

O portfólio como metodologia de avaliação do aprendizado teve inicio a partir das novas concepções sobre significado de avaliação nos cursos de graduação e pós-graduação, na qual organizavam uma coleção de trabalhos produzida pelos estudantes (1), permitindo o processo de crescimento destes. Após algumas reformulações, essa metodologia busca agregar diferentes trabalhos com características teóricas e práticas, possibilitando sair da tradicional forma de avaliação realizada na maioria das instituições de graduação $(2$, 3) disponibilizando um crescimento pessoal e profissional no aluno.

Desta forma, a construção do portfólio pelo aluno tem por objetivo fornecer um registro a médio e longo prazo da evolução do seu rendimento e da sua evolução diante das atividades desempenhadas. Permitindo uma avaliação mais concisa e fidedigna das competências adquiridas pelo aluno durante um certo período. $\mathrm{O}$ aluno desenvolve o trabalho sobre a teoria e a pratica, tornando-se o autor da sua própria avaliação. Ou seja, possibilita a construção da sua própria competência, seja a assimilação de conhecimento, o desenvolvimento de habilidade e o desempenho de atitude apenas pela condução de questões construtivas e reflexivas de forma conjunta com seu avaliador $(3,4)$.

Desta forma, esse método de avaliação não pode ser considerado pelo avaliador apenas como um processo avaliativo numa específica data pré-estipulada, pois é durante o processo de estruturação do portfólio pelo aluno que ocorre o amadurecimento das ideias e assimilação de conhecimento na qual irá desempenhar por meio da habilidade e atitude em prática. Em outras palavras, a elaboração do portfólio procura assegurar o processo de criação e consolidação do conhecimento contextualizado e do desenvolvimento pessoal e profissional dos envolvidos (aluno-avaliador), favorecendo a compreensão dos possíveis significados e a atribuição de sentido(s) às situações vivenciadas na prática e aos conceitos que constituem o cerne da aprendizagem, estimulando o desenvolvimento crítico e reflexivo do aluno (5). Assim, o portfólio viabiliza profissionais críticos, compromissados com as transformações sociais e epidemiológicas, científica e tecnicamente competentes para assumir a comple- 
xidade do cuidar em saúde frente a políticas públicas (6). Reafirmando o papel do portfólio como uma estratégia que potencializa a reflexão de forma sistemática sobre as práticas desenvolvidas pelo autor (7).

Diante dos benefícios trazidos pelo uso do portfólio como método avaliativo e de aprendizagem, bem como a exigência cada vez maior para formação de profissionais qualificados com características como a criatividade, dedicação e um olhar ampliado e diferenciado na saúde, um Programa de Residência Multiprofissional em Sistema Público de Saúde do interior do Rio Grande do Sul, inseriu o portfólio em seu processo de avaliação e de aprendizagem.

Por ser pioneiro entre os programas de Residência Multiprofissional a adotar o portfólio como método avaliativo do pó-graduando, bem como ter a intenção de manter uma avaliação diferenciada da tradicional, questiona-se como foi o processo de construção e elaboração do portfólio como metodologia avaliativa do Programa de Residência Multiprofissional?

Neste sentido, este trabalho tem por objetivo relatar a experiência de construção do portfólio como método de avaliação e aprendizagem prático teórico de um Programa de Residência Multiprofissional em Sistema Público de Saúde por uma residente enfermeira, com o intuito de socializar essa prática inovadora de ensino-aprendizado, a metodologia adotada, a resistências enfrentadas, assim como os resultados e seus desdobramentos.

\section{MÉTODO}

Estudo do tipo relato de experiência, sobre a construção e avaliação do portfólio como metodologia de aprendizagem, adotado pelo Programa de Residência Multiprofissional durante os dois anos de especialização profissional.

O relato esta estruturado conforme os pe- ríodos de maior relevância e de maior motivação, vivenciados pela estudante residente enfermeira haja vista que compartilhar esses períodos pode despertar a motivação de outros Programas de Residência Multiprofissional a optarem pelo portfólio como técnica avaliativa e construtiva que, se empregada com rigor, constitui instrumento de grande valia para o Programa de Pós-graduação, para a instituição de prática, para o aluno e para os preceptores.

Além disso, esses períodos foram associados conforme o fluxograma da metodologia no Programa de Residência, haja vista a construção do portfólio pelo estudante, a avaliação por parte da preceptora, o retorno do parecer e as arguições do estudante. Desta forma, este relato estruturou-se em três fases, construção do portfólio - perspectiva do residente; avaliação do portfólio- perspectiva da avaliação conjunta entre preceptoria/ residente; e o portfólio como instrumento de aprendizagem - visando as potencialidades e as dificuldades na prática desempenhada num programa de residência multiprofissional.

O primeiro período fundamentou-se na construção individual do portfólio pela residente haja vista que o portfólio é a construção e reconstrução da aprendizagem $(3,4)$. Essa etapa era realizada pelo próprio residente num modelo que este próprio estabelecia. Porém, deveria conter as vivencias práticas, alguns referenciais teóricos para que balizasse um pensar critico reflexivo. Assim, a construção do portfólio fazia-se continuo. $\mathrm{Na}$ data pré-estabelecida o portfólio era encaminhado pelo residente via e-mail para a preceptoria. A primeira data estabelecida foi no inicio do segundo semestre do primeiro ano de residência. As demais entregas do portfólio eram a cada 30 dias após o recebimento do parecer avaliativo da preceptoria responsável pela avaliação.

O preceptor, conforme as diretrizes da Residência Multiprofissional era o avaliador de um grupo de residentes que os acompanhava 
nas atividades práticas. Um dos critérios para ser preceptor de campo e consequentemente avaliador dos portfólios, era ter vínculo profissional com o Programa de Residência e com a instituição, bem como possuir domínio dos campos de atuação dos residentes. Além disso, o avaliador deveria fazer um curso para aprimoramento dos processos de trabalho e gestão do residente nos espaços atuantes (5) ministrados pelo programa, visando promover a interação entre as equipes de saúde loco-regional e entre os serviços nos diferentes níveis de atenção, segundo as perspectivas micro e macro políticas ou de gestão (6).

O segundo período de maior relevância para os autores foi a avaliação do portfólio realizada pelo preceptor. Esta etapa se consistiu no período em que o preceptor realiza a leitura do portfólio e por meio de sua experiência profissional emitia um parecer crítico reflexivo, o qual retornava para o autor do portfólio no período de 30 dias.

A terceira etapa foi composta pelo processo de feedback entre preceptoria e residente, na qual constituiu na oportunidade de realizar a análise e discussão dos registros contidos no portfólio, monitorar o crescimento e aprendizagem do estudante. Caracterizando um espaço para a troca de saberes e de construção conjunta do conhecimento diante de uma prática específica representada pela constituição do todo.

\section{RESULTADOS}

Os resultados identificados foram compilados em três etapas, nas quais foram intituladas como: a construção do portfólio, a avaliação do portfólio e o portfólio como instrumento de aprendizagem.

Na etapa de construção do portfólio identificou-se como aspecto positivo e negativos, contudo, esta etapa de construção atendeu aos critérios exigidos pelo programa de residência multiprofissional em saúde. Entretanto a construção final do portfólio agregou uma nova composição, como descrita na Figura 1. Denota-se a partir da estrutura do portfólio do residente, que alguns tópicos não exigidos pelo programa, faziam-se necessários e relevantes para o raciocínio lógico do residente e do preceptor. Um dos tópicos que podemos destacar são os objetivos do programa e as competências do residente, já que são primordiais para justificar a trajetória do residente nos espaços de prática, como destacado pelo residente em seu discurso.

Deste modo, o aspecto positivo da construção do portfólio foi à liberdade do residente para construir seu portfólio haja vista a falta de padronização pelo Programa de Residência induzindo o residente para a sua percepção sobre os aspectos que circundam as atividade do Programa. Os aspectos negativos da construção foram: falta de um modelo pré-estabelecido para a construção do portfólio, bem como a falta de padronização, pois não há um fluxograma no qual o residente possa se basear. E neste sentido, demanda tempo de reflexão na sua construção.

$\mathrm{Na}$ etapa de avaliação do portfólio identificou-se como pontos positivos à presença da preceptora como avaliadora, tendo em vista a sua proximidade com a realidade vivenciada pelo residente. Outro ponto positivo foi a continuidade entre a construção do portfólio e o percurso avaliativo do portfólio.

Um dos pontos considerados negativos desta etapa de avaliação foi a morosidade entre o parecer do preceptor e o envio de novos relatos pelo residente, principalmente por não apresentar um modelo pré-estabelecido pelo Programa de residência e não apresentar um fluxo de avaliação de troca entre o avaliador e o residente.

O fluxo de avaliação relatado neste estudo, descrito na Figura 2, é quando um residente encaminha seu portfólio para o preceptor, que após a sua avaliação, encaminha um pa- 
Figura 1. Estrutura do portfolio.

\begin{tabular}{|c|c|}
\hline & Tópicos identificados no portfólio em estudo \\
\hline & \begin{tabular}{|l} 
APRESENTAÇÃO \\
1.1 Dados pessoais
\end{tabular} \\
\hline & 2 EXPECTATIVAS AO INGRESSAR NA RMI \\
\hline $\begin{array}{l}\text { Tópicos exigidos na estrutura do } \\
\text { portfólio pela Residência }\end{array}$ & $\begin{array}{l}\text { 3. OBJETIVOS DA RMI } \\
\text { 3.1 Objetivos gerais da RMI } \\
\text { 3.2 Objetivos especificos da Área de Concentração: } \\
\text { crônico-degenerativo }\end{array}$ \\
\hline Dados pessoais & 4. COMPETÊNCIAS DO RESIDENTE \\
\hline Trajetória individual (pessoal $\mathrm{e}^{-}$ & $\begin{array}{l}\text { 4.2 Competências especificas do profissional enfermeiro } \\
\text { 5. INTENÇÃO DA CONSTRUÇÃO DO PORTFÓLIO }\end{array}$ \\
\hline & 6. SIGNIFICADO DAS REUNIÕES DE PRECEPTORIA \\
\hline Relato das atividades realizadas no & 6.1 PRECEPTORIA DE CAMPO \\
\hline $\begin{array}{l}\text { decorrer das práticas desenvolvidas na } \\
\text { residência. }\end{array}$ & $\begin{array}{l}\text { 6.2 PRECEPTORIA DE NÚCLEO } \\
\text { 7. VIVÊNCIAS E EXPERIÊNCIAS PROPORCIONADAS } \\
\text { PELARMII }\end{array}$ \\
\hline & $\begin{array}{l}\text { 8. NOSSA PRODUÇÃO GRUPAL (certificado de } \\
\text { eventos/seminários vivenciados) } \\
\text { 9. PARECER DESCRITIVO } \\
\text { 10. REFERENCLAS BIBLIOGRÁFICAS } \\
\text { 11. APÊNDICES } \\
\text { 12. ANEXOS }\end{array}$ \\
\hline
\end{tabular}

Fonte: elaborado pelos autores.

RMI: Programa de Residência Multiprofissional Integrada em Sistema Público de Saúde.

Figura 2. Esquema de avaliação dos portfólios avaliados por uma preceptoria de campo.

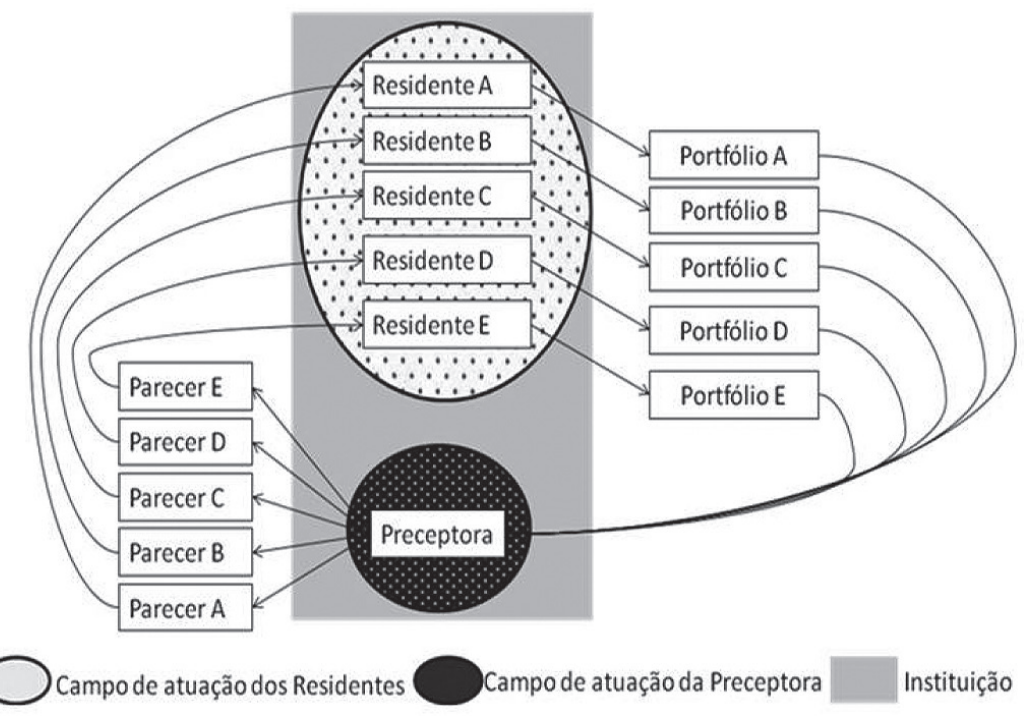

Fonte: elaborado pelos autores. 
recer descritivo individual para cada residente, estabelecendo um ciclo de troca continuo entre o aluno e o avaliador.

Esse fluxo também pode ser visualizado na avaliação individual de cada residente, onde a troca do portfólio só era finalizado após um feedback com o preceptor, no qual auxiliava na aplicabilidade do conteúdo discutido. Deste modo, cada etapa tornava-se morosa da avaliação do portfólio (Figura 3).

$\mathrm{Na}$ última etapa de portfólio como instrumento de aprendizagem identificou-se apenas aspectos positivos. Dentre estes, revela-se que o portfólio é indispensável para a renovação de conhecimentos e competências de forma contínua no aluno, haja vista a os momentos de troca entre todos os envolvidos no Programa de Residência e as relações de trabalho com os membros da equipe, capaz de desenvolver as competências e as dimensões assistencial e gerencial no residente.

\section{DISCUSSÃO E CONCLUSÃO}

Conforme Sá-Chaves (7) portfólio significa compilar trabalhos considerados relevantes, analisá-los e após fundamentá-los com auxílio da literatura. Contudo, no caso da residência multiprofissional em saúde, o sentido do portfólio contemplou descrever dos residentes e sustentar a partir de referenciais teóricos, as possibilidades de melhoria na prática assistencial, educacional e gerencial, como no processo de trabalho instituído na residência e na instituição.

O programa de residência não instituía a adoção de um modelo pré-estabelecido para a construção do portfólio, devido ser pioneiro na implantação desse método. Apenas preconizava inserir os dados pessoais, trajetória individual (pessoal e profissional), e relato das atividades realizadas no decorrer das prá-

Figura 3. Fluxograma do portfólio e parecer.

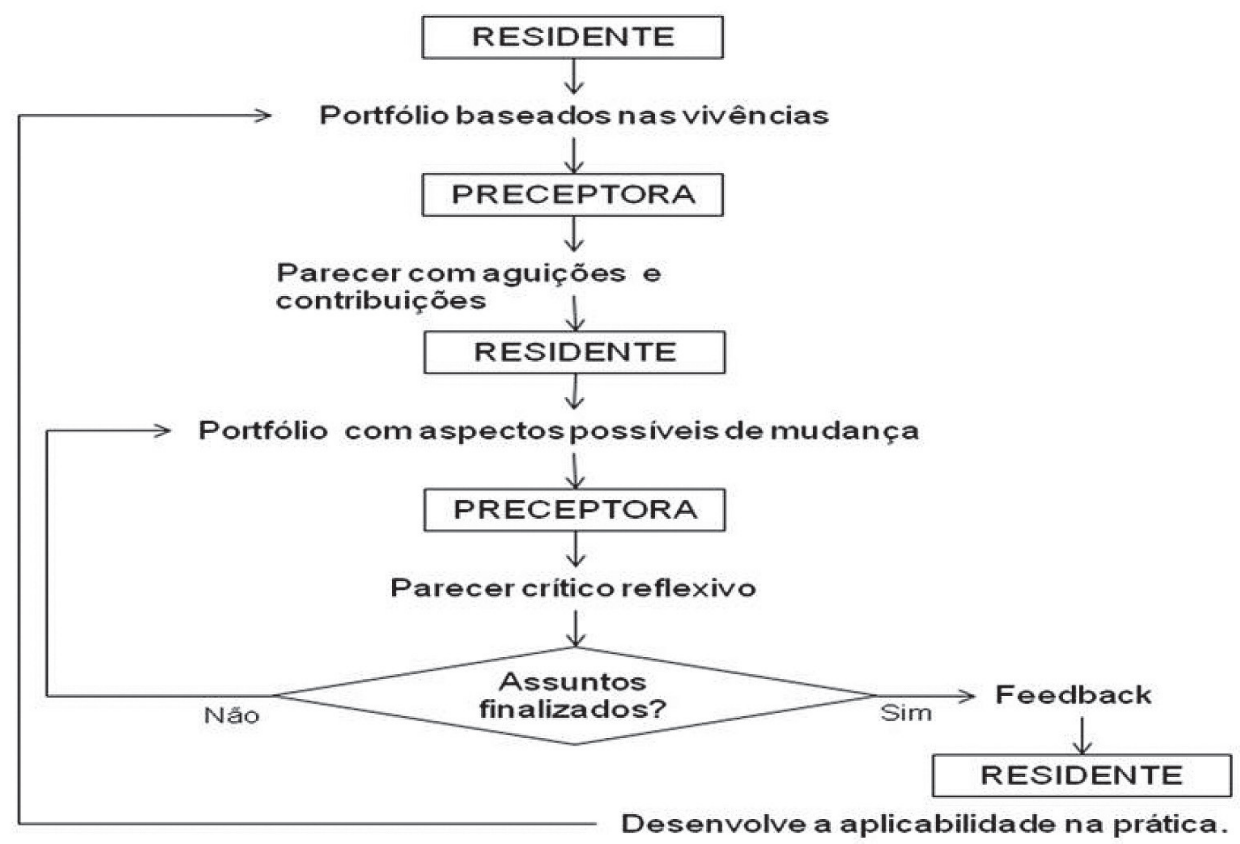

Fonte: elaborado pelos autores. 
ticas desenvolvidas na residência, bem como ter um pensar crítico reflexivo, de forma que o residente transmitisse sua percepção frente ao vivenciado no seu campo de atuação.

A falta de padronização se tornou um desafio na visão do autor, visto que ocorreu a necessidade de rever constantemente os passos seguidos na construção do portfólio, bem como o delineamento dos relatos. Podemos inferir que esta dificuldade está associada ao apego ainda existente sobre a metodologia tradicional que preconiza uma estrutura padrão ou a adoção de avaliações prontas (provas) na qual não tornam o aluno sujeito da sua construção. Desta forma, pode-se pensar que a simples estruturação do portfólio é capaz de provocar discussões no próprio residente sobre um melhor a percurso a seguir, $\mathrm{e}$ consequentemente promover um diferencial em sua produção. Ressaltando que qualquer alteração significativa no processo de formação e desenvolvimento de competências dos profissionais formados aumentam as possibilidades no mercado de trabalho (8).

Ainda ficou evidente pela estrutura do portfólio que o residente buscou uma forma de condução do raciocínio lógico de tempo e espaço, pois buscou as raízes da Política Pedagógica do Programa para conduzir suas vivências. Ou seja, ficou evidente a sua preocupação sobre a adoção dos princípios e diretrizes do Programa que adota ações de gestão e atenção comprometidas num contexto inovador de desenvolvimento loco-regional da saúde (9).

Ao transpor para a área do ensino em enfermagem, pode-se inferir que a estruturação de um portfólio também deve incluir princípios e diretrizes pedagógicos do Programa de Graduação, enfocando os aspectos gerenciais, assistências e de ensino baseados em referenciais teóricos.

A construção do portfólio viabilizou cenários integrados de ensino-aprendizagem, processos assistenciais organizados segundo princípios da regionalização, incluindo dinâmicas mais efetivas de referência e contra referência entre níveis de baixa, média e alta complexidade e, fortaleceu o trabalho interdisciplinar, fomentando a transversalidade, a grupalidade e/ou redes de conversação entre trabalhadores (10), tornando possível a criação de um novo modo de ver e ser na sociedade (11).

Podemos inferir que o método adotado pela residente, permitiu a oportunidade de correlacionar suas atividades curriculares com as práticas sociais na estrutura do portfólio (12). Caracterizando um crescimento profissional que se impõe ao estabelecido, fortalecendo o debater sobre a realidade, pois é capaz de investigar as formas pelas quais as pessoas transformam, tendo como base a realidade como se apresenta (13). E neste ínterim, o residente em enfermagem pode ser um sujeito ativo diante das necessidades de saúde dos sujeitos, principalmente no contexto de Sistema Único de Saúde.

Ainda analisando a construção do portfólio percebe-se que a sua elaboração impulsionou o residente a contrapondo-se as metodologias tradicionais adotando a postura de um sujeito autônomo de seu próprio crescimento sem controle externo (14).

Um estudo desenvolvido com graduandos demonstrou que o uso do portfólio é um instrumento processual e reflexivo (15), na qual traz benefícios construtivos entre o estudante e o professor. $\mathrm{Na}$ realidade da residência, acredita-se que este processo de avaliação possibilita a interação entre residente e preceptor de forma transparente e direta. Contudo, demanda por parte da preceptoria disposição para adotar as metodologias inovadoras, não tradicionais, com vistas a praticar sua autonomia intelectual e condições adequadas de trabalho, despertando no aluno novas formas de visualizar suas práticas.

A partir desta experiência, percebeu-se que a construção do portfólio, vem ao encontro com a estratégia de agregar responsabilidade, empenho, dedicação e aplicabilidade no autor (16), além de estimular o 
pensamento pedagógico reflexivo (17); pois promove oportunidades para refletir, diagnosticar as suas dificuldades, avaliar o seu desempenho e regular a sua própria aprendizagem $(12,17)$.

Um dos pontos negativos da construção do portfólio é a morosidade para construí-lo, pois a sua elaboração demanda tempo e a internalização do pensamento critico-reflexivo no residente, visto que ao relatar cada tópico vivenciado há necessidade de se afastar do objetivo principal e refletir sobre o contexto (3). A avaliação do portfólio demanda reformulações e consolidação de conhecimento, contribuindo com a morosidade do processo de construção e avaliação do portfólio, principalmente em compreender como um ciclo de troca continuo entre o aluno e o avaliador (18). Além disso, o avaliador e o avaliado tornam-se sujeitos participativos ativos na construção do método avaliativo (19), quebrando o modelo tradicional que bloqueia a interação do aluno com o educador.

Para minimizar esta morosidade pode se utilizar o diário de campo. Esta facilidade encontrada neste relato que contribuiu para que a morosidade não fosse ainda maior, visto que ao relatar as vivências numa caderneta pessoal já podia pontuar suas concepções sobre a experiência, bem como realizar um esboço da sua construção futura. Ressalta-se que o diário não foi um método avaliativo, nem uma obrigação a ser adotada pelo residente, contudo é destacado porque revela ser uma estratégia de minimizar o tempo de elaboração do portfólio pelo aluno.

A avaliação do portfólio do Programa de residência não possuía um modelo pré-estabelecido, devido estar em período de construção, contudo, a coordenação da residência, após reunião do colegiado, disponibilizou alguns pontos que deveriam ser observados no decorrer do portfólio avaliado. Deveria ser identificado nas falas dos residentes os princípios e diretrizes preconizadas pelo programa buscando pontos de correlação entre o vivenciado na prática pelo residente e o que é preconizado na proposta pedagógica do programa. Também, deveria ser identificado o conhecimento do residente sobre e como alcançar o conceito (conceito-objetivo) perante a conjuntura da residência (conceito-objetivo-contextualizado).

No parecer, o preceptor era livre para descrever seu ponto de vista. Neste existia diferentes questionamentos dependendo de cada situação vivenciada e registrada pelo residente. Alguns questionamentos eram críticos, outros reflexivos, enquanto que outros apenas instigavam a repensar sobre possíveis recomeços, dispondo sugestões que indicavam um ponto ainda não observado pelo residente.

Conforme autores e como preconizado pela Residência Multiprofissional, a avaliação do portfólio, nenhum tópico do portfólio é considerado errado ou certo principalmente por saber que o portfólio é consolidado no decorrer da formação do residente. Diferindo-se da tradicional nota que representa a quantidade de informações adquiridas pelos sujeitos que aprendem em relação à expectativa do avaliador num específico momento (20).

De acordo com alguns autores a avaliação pautada nesta metodologia permite a tomada de decisão para que atos subsequentes sejam encaminhados (2, 20, 21). Para tanto, a função de avaliar acaba motivando o crescimento, a busca por novos teóricos, nos quais subsidiassem a consecução do processo de ensino e aprendizagem.

Deste modo, a função do avaliador acaba assumindo uma nova perspectiva, pois deve assumir várias funções, se torna orientador, tutor, supervisor e mentor, onde planeja, controla, guia, estimula o raciocínio e a postura ativa; analisa o desempenho; aconselha e cuida do crescimento profissional e pessoal; atuando na formação moral do sujeito (22). Assim, o avaliador precisa conciliar objetivos e formas segundo os quais os alunos deva estruturar seus registros visando um dialogo a respeito da condução do portfólio e as definição 
das estratégias desse recurso avaliativo (23).

Esta experiência de construção do portfólio vem ao encontro da proposta do portfólio haja vista a capacidade de despertar ações criativas frente a uma realidade imposta (5). Um dos exemplos é a inserção de apêndices no portfólio, revelando que o autor criava e buscava auxilio de sua preceptora para definir conceitos e pressupostos de suas atividades diárias.

Dentro dessa perspectiva, o portfólio, mesmo sendo uma metodologia individual, ela passa a ser mais do que uma função meramente formal do aluno, pois se torna uma prática avaliativa que estimula, promove, gera avanço e crescimento profissional e setorial. Mais especificamente, possibilita reconstrução contínua entre preceptor e residente, estudante e professor, acadêmico de graduação em enfermagem e professor do magistério superior.

Tal fato, permite compreender que o portfólio se trata de instrumento facilitador para o desenvolvimento de habilidades e atitudes dos residentes (24) e possui implicações pedagógicas que extrapolam os aspectos técnicos e metodológicos e atinge aspectos sociais, éticos e psicológicos importantes. Ou seja, a avaliação centrada nas informações reproduzidas desconsideram desempenhos mais complexos, como os intelectuais, motores, que devem ser apreendidos e aperfeiçoados em tempo de formação, relativos ao curso ou carreira a que se destinam.

Um dos pontos considerados negativos desta avaliação é a morosidade entre o parecer do preceptor e o envio de novos relatos pelo residente, pois enquanto o preceptor esta avaliando o portfólio existem novos pontos a serem discutidos ou finalizados visto que a prática permanece em andamento. Ou seja, existem vivências relatadas no portfólio ao serem encaminhadas ao preceptor estavam em fase de finalização e após o envio do parecer já estavam finalizadas e para tal não podem ser reestruturadas conforme sugestões ou indagações feitas pela preceptoria.
Desta forma, se evidencia uma lacuna entre a avaliação, construção e a prática desenvolvida pelo residente, pois ambas as etapas são morosas. A sugestão cabível seria reuniões presenciais entre residente e preceptor ou um prazo menor de troca, ou, ampliar o numero de preceptores com uma sistematização de leitura para maior resolutividade em relação ao tempo, promovendo o compartilhamento dos principais tópicos levantados pelos preceptores para que ambos possam estar informados dos principais tópicos registrados por cada residente e corroborarem as ideias centrais para a aplicabilidade na prática.

Essa sugestão é ainda mais viável durante os semestres de graduação, principalmente da enfermagem, em disciplinas teóricas-práticas, pois a possibilidade de manter ambientes de discussão nas aulas teóricas impulsionam um ser-fazer diferenciado na prática. Além disso, os professores teóricos por conhecerem o contexto prático, propiciam uma melhor condução das vivências, bem como das possibilidades de melhoria na prática. Conforme Chun e Bahia (15) o professor ao saber das dificuldades e das facilidades do aluno, auxilia no andamento das práticas e no processo de construção do portfólio, além de estimular seu desenvolvimento e autoestima. Estudo revela que o profissional que domina a prática clínica e os aspectos educacionais relacionados a ela, transforma o ambiente em momentos educacionais propícios, podendo indicar as oportunidades de aprendizagem e os cenários de exposição, proporcionando verdadeiras condições de desenvolvimento técnico e ético nos cenários reais de prática profissional (22).

Conforme os autores essa troca de saberes, parece ser benéfica, pois o residente constantemente está em elaboração do portfólio, ou seja, o residente está sempre alimentando seus relatos, por vezes, em decorrência de maior explanação por parte da avaliação ou por ter vivenciado alguma prática relevante. Mostrando que esse diferencial contribui com o andamento deste processo de 
aprendizado constante, que muitas vezes se busca durante a formação de um acadêmico de graduação.

Desta forma, a construção do portfólio e o percurso avaliativo do residente aconteciam de forma contínua, assumindo um espaço singular seja pela expressão do aluno sobre o seu processo de aprendizagem (suas impressões, leituras, achados e olhar auto avaliativo), seja por ter representado momentos de diálogo entre equipe multiprofissional, em contínuos movimentos de discussão e análise. Num estudo similar, a construção do portfólio e da avaliação também foi de forma dinâmica e interativa, contudo apresentava um instrumento de avaliação no qual esta vivencia não apresentou (25).

As situações organizacionais de aprendizagem constante são indispensáveis para a renovação de conhecimentos e competências tanto a nível individual como organizacional (26), uma vez que permitem a renovação contínua no aluno. O desenvolvimento do portfólio pode contribuir com o progresso à docência como relatado numa experiência no Estado do Rio Grande do Sul - Brasil (27). Contudo, para que a aprendizagem ocorra de forma produtiva, os indivíduos precisam estar predispostos a enfrentar e selecionar estratégias diante dos desafios que servem como estímulos para uma dada reação, de acordo com sua compreensão cognitiva e efetiva do significado do estímulo (28).

Conforme exposto pelos autores, parece compreensível que educadores questionem os processos de avaliação que colocam em prática e que espelham algo sobre os valores educativos que estão em jogo no momento atual. Isso tem gerado campo propício ao esforço de inovação dos processos de avaliação e apontam o portfólio como uma alternativa interessante, pois implica a apropriação da avaliação como componente de um trabalho pedagógico reflexivo e participativo.

Acredita-se que a inovação do processo de avaliação possibilita um momento de troca perante as relações de trabalho com os mem- bros da equipe, se conhece gradativamente o trabalho do profissional na sua magnitude, desenvolvendo as competências e as dimensões assistencial e gerencial. Ou seja, torna-se um momento onde o educador e o educando atuam com o portfólio como instrumento estratégico de desenvolvimento e execução das atividades, sustentadas por uma práxis visando o pensamento reflexivo e ativo; acrescidos de uma percepção crítica da realidade buscando a essência dos processos, continuidade-ruptura, elaboração do objeto por meio da análise, historicidade que destaca a síntese de cada momento que é fruto de um processo histórico que pode ser superado por novas sínteses, totalidade e articulação do conhecimento adquirido com a realidade (29).

Outro ponto importante do portfólio é a associação que a sua construção apresenta perante a aprendizagem centrada nas competências, pois se aprende fazendo (30). $\mathrm{Na}$ realidade da enfermagem, essa associação possibilita um ser-fazer agregando as dimensões de atitude, habilidade e conhecimento, conhecidas como do aprendizado.

Este relato revela que o responsável pela correção do portfólio não é meramente um avaliador, pois além de destacar os pontos fortes do aluno, auxilia no aprimoramento das práticas adotadas em seu processo de trabalho. Mais especificamente, revela o preceptor como educador, oferecendo, ao residente, ambientes que lhe permitam construir e reconstruir conhecimentos (22), além de desenvolver as habilidades gerenciais, competência profissional e mudanças nos processos de trabalho $(5,31)$.

A avaliação deste relato não teve um fechamento completo como preconizado na literatura, pois a avaliação final do ultimo portfólio não foi avaliada, bem como respondida com um parecer do preceptor. Contudo, ressalta-se que as últimas práticas relatadas no portfólio foram diferenciadas, pois se basearam na construção e finalização do trabalho de conclusão de curso, pois é uma exigência parcial para obtenção do título de 
especialista. Assim, a avaliação do portfólio abrangeu até a construção do projeto de pesquisa.

No entanto, ficou evidente que o portfólio é um instrumento de aprendizagem na qual possibilita um pensar crítico-reflexivo do residente, o que torna o processo de reflexão como o componente principal para crescimento profissional, com vistas a mudar práticas tradicionais.

Sugere-se maior estudo sobre o uso do portfólio na visão do residente e do preceptor considerado do ponto de vista dos autores relatores deste estudo como educador, visando melhorias na comunicação entre ambos, visto que a morosidade na construção do portfólio, bem como na sua avaliação pode ser um ponto negativo neste método de avaliação. Contudo, os pontos positivos desta forma de avaliação são essenciais para a formação de um profissional que prime por ações pautadas numa lógica fomentada no pensamento crítico, moderno, intelectual e acima de tudo desprovido da característica tradicional do fazer saúde, modelo enraizado nos campos práticos do Sistema Único de Saúde.

Para tal, acredita-se que a metodologia de aprendizagem proposta pelo Programa de Residência Multiprofissional seja aperfeiçoada, mas que se mantenha o uso do portfólio durante a formação profissional desses estudantes.

\section{REFERÊNCIAS}

1. Rees C. The use (and abuse) of the term 'portfolio'. Med Educ. 2005; 39(4): 436-8.

2. Albertino FMF, Souza NA. Avaliação da aprendizagem: o portfólio como auxiliar na construção de um profissional reflexivo. Estudos em Avaliação Educacional. 2004; 29, (s/n), 169-89.

3. Santamaría JS. El e-portafolio en la docencia universitaria: percepciones de los estudiantes y carga de trabajo. Revista Electrónica de Investigación y Docencia (REID). 2012; 7: 31-55.

4. Otrenti E, Jodas DA, Silva LG da, Aguilera TK da C, Vannuchi MTO. Portfólio reflexivo como método de avaliação na residência de gerência de serviços de enfermagem. Semina: Ciências Biológicas e da Saúde. 2011; 32(1): 41-46.

5. Silva RF da, Sá-Chaves I. Formação reflexiva: representações dos professores acerca do uso de portfólio reflexivo na formação de médicos e enfermeiros. Interface (Botucatu). 2008; 12(27): 721-34.

6. Malta DC, Merhy EE. O percurso da linha do cuidado sob a perspectiva das doenças crônicas não transmissíveis. Interface (Botucatu). 2010; 14(34): 593-605.

7. Sá-Chaves I (org.) Formação, conhecimento e supervisão: contributos nas áreas da formação de professores e de outros profissionais. Aveiro: Universidade de Aveiro; 2000. (Estudos temáticos 1).

8. Cavalheiro MTP, Guimarães AL. Formação para o SUS e os Desafios da Integração Ensino Serviço. Caderno FNEPAS. 2011, 1: 10-22.

9. Merhy EE, Feuerwerker LC, Macruz SE. Contribuciones metodológicas para estudiar la producción del cuidado en salud: aprendizajes a partir de una investigación sobre barreras y acceso en salud mental. Salud colect. 2012; 8(1): 25-34.

10. Merhy EE, Onocko R. Agir em saúde: um desafio para o público. São Paulo: Hucitec; 2007.

11. Frota MMA, Menezes LMB, Alencar $\mathrm{CH}$, Jorge LS, Almeida MEL. O portfólio como estratégia facilitadora do processo de ensino-aprendizagem para a formação em odontologia: Adequação de metodologias de ensino utilizando o ambiente virtual de aprendizagem. Rev. ABENO. 2011; 11(1): 23-8.

12. Villas Boas BMF. Portfólio, avaliação e trabalho pedagógico. Campinas, SP: Papirus; 2004. 
13. Moraes JT, Lopes EMT. A formação de profissionais de saúde em instituiçõoes de ensino superior de Divinópolis, Minas Gerais. Trab. educ. saúde. 2009; 7(3): 435-44.

14. Mcmullan M, Endacott R, Gray MA, Jasper M, Miller CML, Scholes J, et al. Portfolios and assessment of competence: a review of the literature. J Adv Nurs. 2003; 41(3): 283-94.

15. Chun RYS, Bahia MM. O uso do portfólio na formação em fonoaudiologia sob o eixo da integralidade. Rev. CEFAC. 2009; 11(4): 688-94.

16. Sá-Chaves I. (Org.) Os "portfólios” reflexivos (também) trazem gente dentro: reflexões em torno do seu uso na humanização dos processos formativos. Porto: Porto Editora; 2005.

17. Nunes A, Moreira A. O "portfólio" na aula de língua estrangeira: uma forma de aprender e a ser (para alunos e professores). En: Sá-Chaves I. (org.). Os “portfólios” reflexivos (também) trazem gente dentro: reflexões em torno do seu uso na humanização dos processos formativos. Porto: Porto Editora; 2005. p. 51-66.

18. Moreira JR, Ferreira MJ. Webfolios reflexivos: contributos para o desenvolvimento profissional do professor. Educação, Formação \& Tecnologias. 2011; 4(2): 6175.

19. Sordi MRL, Silva MM. O uso de portfólios na pedagogia universitária: uma experiência em cursos de enfermagem. Interface (Botucatu). 2010; 14(35): 943-53.

20. Luckesi C. A avaliação da aprendizagem escolar. São Paulo: Cortez; 1995.

21. Cotta RM, Silva LS, Lopes LL, Gomes KO, Cotta FM, Lugarinho R, Mitre SM. Construção de portfólios coletivos em currículos tradicionais: uma proposta inovadora de ensino-aprendizagem. Cien Saude Colet. 2012; 17(3): 787-96.

22. Botti SHO, Rego STA. Docente-clínico: o complexo papel do preceptor na residência médica. Physis. 2011; 21(1): 65-85.

23. Rosa JS, Silva GP, Wilhelm FA, Deon APR.
Portfólio no processo de avaliação da aprendizagem no ensino superior: uma análise cartográfica das convergências com a educação biocêntrica. Revista Eletrônica de Pesquisa e Docência (REID). 2013; 10(1): 181-204.

24. Morais CS. Cenários da libertação: Paulo Freire na prisão, no exílio e na universidade. Porto Velho, RO: Editora da Universidade Federal de Rondônia; 2009. 262p.

25. Bona AS de, Basso MVA. Portfólio de Matemática: um instrumento de análise do processo de aprendizagem. BOLEMA. 2013; 27(46): 399-416.

26. Le Boterf G. Desenvolvendo a competências dos profissionais. Porto Alegre: Artmed; 2003.

27. Ribeiro MD, Rêgo ZLGP, Ribeiro MD, Silva EGF da, Souza AAO. Da leitura coletiva ao portfólio: um modo de ler e expressar ideias sobre o texto literário. Anais do Salão Internacional de Ensino, Pesquisa e Extensão. 2013; 5(1): 10.

28. Corrêa EA, Guimarães TA, Bido DS. Dimensões de aprendizagem em organizações: validação do dimensions of the learning organizations questionnaire (DLOQ) no contexto brasileiro. Rev. Adm. Mackenzie. 2011, 12(2): 4-29.

29. Prado C, Freitas GF, Pereira IM, Mirai VL, Leite MMJ. Avaliação no estágio curricular de administração em enfermagem: perspectiva dialética. Rev Bras Enferm. 2010; 63(3): 487-90.

30. Cotta RMM, Costa GD da, Mendonça ET. Portfólio reflexivo: uma proposta de ensino e aprendizagem orientada por competências. Cien Saude Colet. 2013; 18(6): 1847-56.

31. Feuerwerker LCM, Merhy EE. Como temos armado e efetivado nossos estudos, que fundamentalmente investigam políticas e práticas sociais de gestão e de saúde? En: Mattos RA, Baptista TWF (orgs.). Caminhos para análise das políticas de saúde. Río de Janeiro: IMS/UERJ; 2011.p 290-305. 